\title{
Cost-effectiveness analysis of colorectal cancer screening with stool DNA testing in intermediate-incidence countries

\author{
Grace Hui-Min Wu ${ }^{1,2}$, Yi-Ming Wang ${ }^{2}$, Amy Ming-Fang Yen², Jau-Min Wong3, \\ Hsin-Chih Lai ${ }^{4}$, Jane Warwick ${ }^{5}$ and Tony Hsiu-Hsi Chen*2,6
}

Address: ${ }^{1}$ Graduate Institute of Epidemiology, College of Public Health, National Taiwan University, Taipei, Taiwan, ${ }^{2}$ Institute of Preventive Medicine, College of Public Health, National Taiwan University, Taipei, Taiwan, ${ }^{3}$ Department of Internal Medicine, National Taiwan University Hospital, Taipei, Taiwan, ${ }^{4}$ School of Medical Technology, College of Medicine, National Taiwan University, Taipei, Taiwan, ${ }^{5}$ Cancer Research UK Department of Epidemiology, Mathematics and Statistics, Wolfson Institute of Preventive Medicine, Queen Mary University of London, UK and ${ }^{6}$ Division of Biostatistics, Graduate Institute of Epidemiology, College of Public Health, National Taiwan University, Taiwan

Email: Grace Hui-Min Wu - gracewu@ntu.edu.tw; Yi-Ming Wang - cls@ms4.hinet.net; Amy Ming-Fang Yen - mfyen@episerv.cph.ntu.edu.tw; Jau-Min Wong - jmwong@ha.mc.ntu.edu.tw; Hsin-Chih Lai - hclai@ha.mc.ntu.edu.tw; Jane Warwick - jane.warwick@cancer.org.uk; Tony HsiuHsi Chen* - stony@episerv.cph.ntu.edu.tw

* Corresponding author

Published: 24 May 2006

BMC Cancer 2006, 6:136 doi:10.1186/147|-2407-6-136

This article is available from: http://www.biomedcentral.com/147/-2407/6/136

(C) 2006 Wu et al; licensee BioMed Central Ltd.

This is an Open Access article distributed under the terms of the Creative Commons Attribution License (http://creativecommons.org/licenses/by/2.0), which permits unrestricted use, distribution, and reproduction in any medium, provided the original work is properly cited.
Received: 04 November 2005

Accepted: 24 May 2006

\begin{abstract}
Background: The aim of this study is to compare the cost-effectiveness of screening with stool DNA testing with that of screening with other tools (annual fecal occult blood testing, flexible sigmoidoscopy every 5 years, and colonoscopy every 10 years) or not screening at all.

Methods: We developed a Markov model to evaluate the above screening strategies in the general population 50 to 75 years of age in Taiwan. Sensitivity analyses were performed to assess the influence of various parameters on the cost-effectiveness of screening. A third-party payer perspective was adopted and the cost of $\$ 13,000$ per life-year saved (which is roughly the per capita GNP of Taiwan in 2003) was chosen as the ceiling ratio for assessing whether the program is costeffective.

Results: Stool DNA testing every three, five, and ten years can reduce colorectal cancer mortality by $22 \%, 15 \%$, and $9 \%$, respectively. The associated incremental costs were $\$ 9,794, \$ 9,335$, and $\$ 7,717$, per life-year saved when compared with no screening. Stool DNA testing strategies were the least cost-effective with the cost per stool DNA test, referral rate with diagnostic colonoscopy, prevalence of large adenoma, and discount rate being the most influential parameters.

Conclusion: In countries with a low or intermediate incidence of colorectal cancer, stool DNA testing is less cost-effective than the other currently recommended strategies for population-based screening, particularly targeting at asymptomatic subjects.
\end{abstract}

\section{Background}

Because of the high incidence, long preclinical period, and availability of treatment which gives a favorable prognosis with early diagnosis, screening for colorectal cancer (CRC) has been shown to lead to substantial mortality reductions in Western countries; $15-33 \%$ with fecal occult blood testing (FOBT), 33\% with flexible sigmoidoscopy and 57\% with colonoscopy [1-7]. The U.S. Multisociety 
Task Force on Colorectal Cancer has therefore recommended multiple options for screening people at average risk of CRC including annual FOBT, flexible sigmoidoscopy every 5 years, and colonoscopy every 10 years [8].

Given this choice of effective screening tools, the deciding factor amongst alternatives could be efficacy, performance (sensitivity and specificity), acceptability, feasibility, compliance, and clinical capacity. Colonoscopy, for example, has been recommended as one of the screening options in the USA because of high sensitivity and specificity [8]. However, in countries with a shortage of medical endoscopic manpower the resulting increased demand for colonoscopy may render such a scheme unworkable. In addition, the uptake of colonoscopy is likely to depend upon local social and cultural issues.

Recently, a new method for detecting adenoma and invasive CRC, known as stool DNA testing, has been suggested as a potential screening tool $[8,9]$. It analyzes the DNA contained in stools, through natural exfoliation, and detects alterations. The sensitivity of stool DNA testing, based on symptomatic cases, has been reported as between $36 \%$ and $82 \%$ for advanced adenoma and between $61 \%$ and $100 \%$ for invasive cancer, and the specificity has been estimated at between $89 \%$ and $100 \%$ in clinical studies [10-15]. A recent large prospective study, targeting average-risk, asymptomatic subjects aged 50 years or older, reported more conservative results when using stool DNA testing as a screening tool; sensitivities of $15 \%$ and $52 \%$ respectively for adenoma and invasive cancer [16]. Nevertheless, stool DNA testing was found significantly better than the fecal occult blood test [16]. Since the costs associated with stool DNA testing are considerable the issue of whether the required expenditure could be offset by future savings (brought about by a reduction in the number of advanced cases needing treatment) must be addressed before stool DNA testing, as a populationbased screening tool for average-risk, asymptomatic subjects, can be introduced. This is particularly important for countries with a low or intermediate, but nevertheless dramatically increasing, incidence of CRC.

In Taiwan for instance, CRC has been ranked as the fourth most common cancer and accounted for $11 \%$ of cancer cases and $12 \%$ of cancer deaths in 2000 [17]. The ageadjusted incidence has increased by 50\%, from 19.4 per 100,000 in 1995 to 28.3 per 100,000 in 2000 , while the associated mortality has increased from 11.3 to 12.7 per 100,000 .

The aim of this study is therefore to perform a decision analysis using a Markov model to compare the effectiveness and cost of stool DNA testing with other conventional screening strategies. The cost-effectiveness analysis compares triennial, five-yearly, and ten-yearly stool DNA testing $\left(\mathrm{DNA}_{3}, \mathrm{DNA}_{5}\right.$, and $\mathrm{DNA}_{10}$ ), with no screening (No Screening), annual FOBT (FOBT 1 ), five-yearly flexible sigmoidoscopy $\left(\mathrm{SIGM}_{5}\right)$, and ten-yearly colonoscopy $\left(\mathrm{COLO}_{10}\right)$.

\section{Methods \\ Model specification}

We developed a Markov model by using DATA Version 3.5 (TreeAge Software) to consider several screening strategies for $\mathrm{CRC}$, including $\mathrm{DNA}_{3}, \mathrm{DNA}_{5}, \mathrm{DNA}_{10}, \mathrm{FOBT}_{1}$, $\mathrm{SIGM}_{5}, \mathrm{COLO}_{10}$, and No Screening. Subjects at averagerisk of developing CRC were screened from age 50 years until age 75 or death. For each Markov decision, all possible transition states radiated from the decision node with 1-year Markov cycles. Effectiveness was defined as additional life-years gained as a result of screening.

The disease natural history of CRC was simulated by a nine-state Markov model (Figure 1) consisting of normal, small adenoma (adenoma smaller than $1 \mathrm{~cm}$ in size), large adenoma (adenoma larger than $1 \mathrm{~cm}$ in size), preclinical early CRC (preclinical Dukes' stage A and B CRC), preclinical late CRC (preclinical Dukes' stage $\mathrm{C}$ and $\mathrm{D}$ ), clinical early CRC, clinical late CRC, CRC death, and other cause of death. Our model only focuses on modeling adenoma-carcinoma sequences without considering nonpolypoid CRC because information on the sensitivity and specificity of the screening tool for detecting the nonpolypoid form is unclear. The progression from each state to the next follows a Markov process that assumes that transition depends only on the current state, i.e. the process has no memory. The solid arrows represent the direct transition between states, and the dotted ones the transition toward other cause of death. The transition rates are denoted as $\lambda_{1}(\mathrm{t}), \lambda_{2}, \ldots, \lambda_{8}$, and $\mu(\mathrm{t})$ where, for example, $\lambda_{2}$ is the annual transition rate from small to large adenoma, and $\mu(\mathrm{t})$ is the annual age-specific mortality rate from other causes. Note that as the annual incidence rate of small adenoma increases with age we allow it to vary with time according to the Weibull distribution denoted as $\lambda_{1}(\mathrm{t})$, i.e. annual incidence rate of small adenoma in subjects aged $t$. The hazard function for the Weibull distribution is

$\lambda_{1}(\mathrm{t})=\lambda_{10} \gamma \mathrm{t}^{\gamma-1}$

where $\lambda_{10}$ and $\gamma$ are the scale and shape parameters respectively. We assume the other transition parameters, $\lambda_{2}-\lambda_{8}$, are constant over time. The estimated transition rates are shown in Table 1.

Following Cox and Miller [18], Duffy et al [19] and Chen et al [20], the corresponding annual transition probabilities from one state to another can be obtained by convert- 


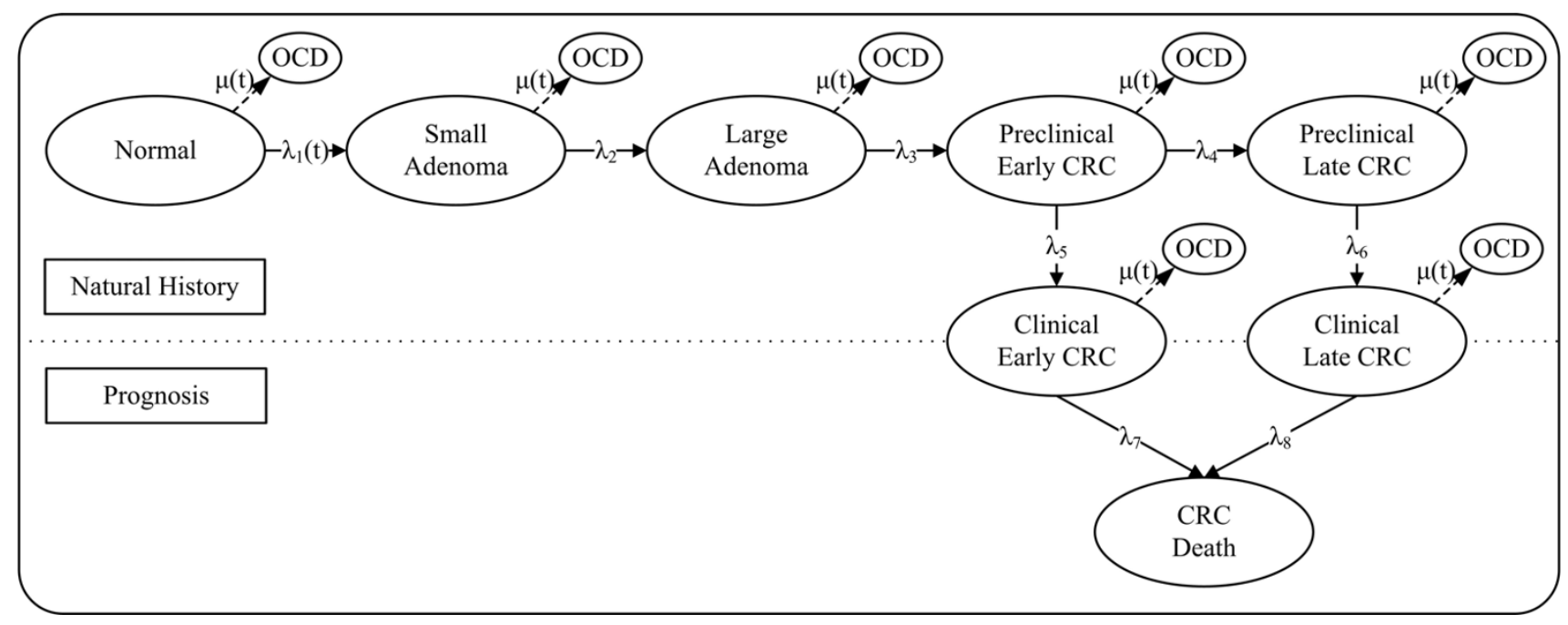

\section{Figure I}

Markov process for disease natural history and prognosis of colorectal cancer (CRC).** The ovals represent Markov states; the solid arrows represent the direct transition between states, and the dotted arrows represent the transition toward competing cause of death. Abbreviations: Small adenoma, adenoma smaller than I cm in size; large adenoma, adenoma larger than I $\mathrm{cm}$ in size; early CRC, Dukes' stage A and B colorectal cancer, late CRC, Dukes' stage C and D colorectal cancer; OCD, other cause of death.

ing the transition rates. The Markov model specifying the transitions between states in Figure 1 illustrates the progressive property of model. At any instant a one-step transition from small adenoma to clinical CRC is not allowed but a multi-step transition is possible, although the likelihood of transition from small to large adenoma, and from large adenoma to pre-clinical CRC, within a year starts low but increases with time. To build this feature into our model, we allowed multiple-step transitions even within one cycle to be possible although the chance is low. Thus, although small adenoma has only a slim chance of progressing through large adenoma, preclinical early CRC, and then to clinical early CRC chronologically within one cycle but our model nevertheless allows for the possibility. Furthermore, since we wanted to simulate a screening scenario, the initial state may be normal, adenoma, or preclinical CRC with the corresponding prevalences at age 50 years. However, there are still lines emanating from the root Markov node to clinical CRC, CRC death, and other death, but the probabilities of these states at the first cycle (initial probabilities) are all zero.

\section{Description of screening strategies}

The "No Screening" strategy follows the disease natural history. The screening procedures for other screening strategies are shown in Figure 2. In stool DNA screening strategies, subjects in the normal, adenoma, or preclinical phase of CRC states will be offered screening but may, or may not, take up stool DNA testing. After modeling the uptake of stool DNA testing, the number of detected cases of adenoma or preclinical CRC is determined by the sensitivity and specificity. A proportion of subjects with positive stool DNA test results will undergo further examination (colonoscopy to detect adenoma and preclinical CRC) as fixed by the compliance rate. The complications of perforation and death due to colonoscopy are also taken into account. Subjects who do not participate in stool DNA testing, those with false negative results and those who refuse diagnostic colonoscopy will return to the disease natural history. Subjects detected with adenoma follow the surveillance procedure and screendetected cases of CRC follow the prognosis of CRC. The Markov decision model for FOBT screening and sigmoidoscopy screening is similar to that for screening by stool DNA testing, but with different values for sensitivity and specificity. With colonoscopy screening, the procedure for positive results or the surveillance of adenoma is also similar to that for stool DNA testing screening, except that polyps detected with colonoscopy will be removed directly.

Adenoma detected by screening will be removed by polypectomy during first colonoscopy. In the light of the American Cancer Society guidelines on screening and surveillance for the early detection of colorectal adenomas and cancer, the removal of adenoma will be followed up with surveillance [9]. Any recurrence of neoplasm will follow the disease natural history. Subjects with small ade- 
Table I: Base-case estimates and ranges used in sensitivity analysis

\begin{tabular}{|c|c|c|}
\hline Variable & Base-Case Values (Range) & Reference \\
\hline \multicolumn{3}{|l|}{ The disease natural history and prognosis } \\
\hline \multicolumn{3}{|l|}{ Prevalence of colorectal neoplasm at age 50 years } \\
\hline Small adenoma & $9.28 \%(4.64 \%-18.56 \%)$ & $2-4,17,21^{*}$ \\
\hline Large adenoma & $3.82 \%(0.96 \%-7.64 \%)$ & $2-4,17,21^{*}$ \\
\hline Preclinical early CRC & $0.12 \%(0.06 \%-0.24 \%)$ & $2-4,17,21^{*}$ \\
\hline Preclinical late CRC & $0.08 \%(0.04 \%-0.16 \%)$ & $2-4,17,21 *$ \\
\hline \multicolumn{3}{|l|}{ Annual transition rates } \\
\hline \multicolumn{3}{|l|}{ Normal to small adenoma $\left(\lambda_{1}(\mathrm{t})\right)$} \\
\hline at age 50 years & $0.00836(0.00418-0.01672)$ & $2-4,17,21^{*}$ \\
\hline at age 55 years & $0.00990(0.00495-0.01980)$ & $2-4,17,21^{*}$ \\
\hline at age 60 years & $0.01156(0.00578-0.02312)$ & $2-4,17,21^{*}$ \\
\hline at age 65 years & $0.01333(0.00667-0.02666)$ & $2-4,17,21^{*}$ \\
\hline at age 70 years & $0.01521(0.00761-0.03042)$ & $2-4,17,21^{*}$ \\
\hline Small adenoma to large adenoma $\left(\lambda_{2}\right)$ & $0.0346(0.0173-0.0692)$ & $2-4,17,21^{*}$ \\
\hline Large adenoma to preclinical early CRC $\left(\lambda_{3}\right)$ & $0.0215(0.0108-0.0430)$ & $2-4,17,21^{*}$ \\
\hline Preclinical early CRC to preclinical late CRC $\left(\lambda_{4}\right)$ & $0.3697(0.2678-0.4715)$ & 22 \\
\hline Preclinical early CRC to clinical early CRC $\left(\lambda_{5}\right)$ & $0.2382(0.2055-0.2709)$ & 22 \\
\hline Preclinical late $C R C$ to clinical late $\operatorname{CRC}\left(\lambda_{6}\right)$ & $0.4852(0.3207-0.6498)$ & 22 \\
\hline Early CRC to CRC death $\left(\lambda_{7}\right)$ & $0.0302(0.0151-0.0604)$ & $2-4,23$ \\
\hline Late CRC to CRC death $\left(\lambda_{8}\right)$ & $0.2099(0.1050-0.4198)$ & $2-4,23$ \\
\hline
\end{tabular}

Screening and diagnostic test characteristics

\begin{tabular}{|c|c|c|}
\hline Flexible sigmoidoscopy reach & $50(50-60)$ & 25 \\
\hline \multicolumn{3}{|l|}{ Sensitivity, \% } \\
\hline \multicolumn{3}{|l|}{ Stool DNA testing } \\
\hline Small adenoma & $8(5-75)$ & 16 \\
\hline Large adenoma & $15(12-82)$ & $10-12,16$ \\
\hline Preclinical CRC & $52(50-100)$ & $10-12,16$ \\
\hline \multicolumn{3}{|l|}{ FOBT } \\
\hline Small adenoma & $5(2-10)$ & $26-31$ \\
\hline Large adenoma & $10(5-20)$ & $26-31$ \\
\hline Preclinical CRC & $50(13-90)$ & $26-31$ \\
\hline \multicolumn{3}{|l|}{ Flexible sigmoidoscopy and colonoscopy } \\
\hline Small adenoma & $78.5(73-84)$ & 25 \\
\hline Large adenoma & $85(85-90)$ & 25 \\
\hline Preclinical CRC & $95(90-100)$ & $25,32-38$ \\
\hline \multicolumn{3}{|l|}{ Specificity, \% } \\
\hline Stool DNA testing & $94(89-100)$ & $10-12,16$ \\
\hline FOBT & $97.5(95-100)$ & $2-4$ \\
\hline Flexible sigmoidoscopy & $94(92-96)$ & 25 \\
\hline Colonoscopy & $98(96-100)$ & 25 \\
\hline \multicolumn{3}{|l|}{ Complication of colonoscopy } \\
\hline Perforation rate, $\%$ & $0.2(0.07-0.85)$ & $39-40$ \\
\hline Death rate due to perforation, per 100,000 & $10(0-50)$ & $39-40$ \\
\hline
\end{tabular}

\section{Costs, $\$$}


Table I: Base-case estimates and ranges used in sensitivity analysis (Continued)

\begin{tabular}{lcc}
\hline Screening & & \\
Stool DNA testing & $44.1(22.1-88.2)$ & Expert opinion \\
FOBT & $0.6(0.3-1.2)$ & BNHI \\
Flexible sigmoidoscopy & $35.3(17.6-70.6)$ & BNHI \\
Colonoscopy & $66.2(33.1-161.8)$ & BNHI \\
\hline Treatment and confirmation & & BNHI \\
Pathological examination & $20.6(10.3-41.2)$ & BNHI \\
Biopsy & $13.2(6.6-26.5)$ & BNHI \\
Colonoscopy & $66.2(33.1-161.8)$ & BNHI \\
Polypectomy & $42.4(21.2-84.7)$ & BNHI \\
Initial cost for early CRC & $3117.6(1558.8-6235.3)$ & BNHI \\
Initial cost for late CRC & $7705.9(3852.9-15411.8)$ & BNHI \\
Continuing cost for CRC & $176.5(88.2-352.9)$ & BNHI \\
Terminal Care for CRC & $7647.1(3823.5-15294.1)$ & BNHI \\
Complication cost for perforation & $1617.6(808.8-3235.3)$ & BNHI \\
Complication cost for death & $2735.3(1367.6-5470.6)$ & \\
\hline Discount rate, \% & $3(0-7)$ & \\
\hline
\end{tabular}

Abbreviations: CRC, colorectal cancer; FOBT, fecal occult blood testing; BNHI, Bureau of National Health Insurance.

* The estimates were obtained and re-estimated by combining several data sources $[2-4,17,21]$.

noma will receive colonoscopy after 5 years. Then, if normal, they return to the normal state in the natural history and are screened according to the standard screening strategies. A similar procedure is applied to subjects found to have a large adenoma. They will receive colonoscopy three years after the initial polypectomy and, assuming no adenoma after two repeated colonoscopies, return to the normal state in the natural history mode.

\section{Base-case estimates}

Base-case estimates of the disease natural history and prognosis, screening and diagnostic test characteristics, and costs for cost-effectiveness analysis were abstracted from published literature and are listed in Table 1 . Note that the base-case estimates of sensitivity and specificity of stool DNA testing were obtained from the Imperiale et al [16] study that has been so far the only one considering average risk asymptomatic subjects aged 50 years.

\section{Transition parameters}

Parameters for the disease natural history and prognosis were derived from previous studies [2-4,17,22-24]. The transition rates between various invasive carcinoma states, $\lambda_{4}-\lambda_{6}$, were obtained from selective screening for CRC, the Taiwan Multicenter Cancer Screening (TAMCAS) Project [21]. Regarding prevalence rate of adenoma, the prevalence estimates for large adenoma in previous randomised trials [2-4] and the cumulative risk of 35\% at 20 years of carcinoma developing from large adenoma [21] coupled with the age-specific CRC incidence rates in Taiwan in 2000 [17], were used to project the age-specific preclinical incidence of small adenoma, $\lambda_{1}(\mathrm{t})$ (assuming a Weibull distribution), the transition rate from small to large adenoma, $\lambda_{2}$, (assuming an exponential distribution) and the transition rate from large adenoma to preclinical early CRC [22], $\lambda_{3}$ (assuming an exponential distribution). The estimated age-specific preclinical incidences of small adenoma are shown in Table 1. Assuming survival time follows exponential distribution, the parameters for survival with clinical CRC, $\lambda_{7}$ and $\lambda_{8}$, were derived from the survival probabilities for each stage of CRC [23] after weighting the distribution of CRC stage among the control groups according to previous studies [2-4]. Age-specific mortality, $\mu(\mathrm{t})$, for other cause of death, refer to Taiwan's vital statistics in 2002 [24]. The prevalence of colorectal neoplasm at age 50 years was obtained by converting the transition rates mentioned above and are shown in Table 1.

\section{Test characteristics}

The estimated parameters for test characteristics such as sensitivity, specificity, and complication with colonoscopy were derived from previous studies [2-4], [10$14,16,25-40]$. This sensitivity is allowed to vary with state. The base-case estimates of sensitivity of stool DNA testing were $8 \%$ for small adenoma, $15 \%$ for large adenoma and $52 \%$ for invasive cancer [16]. The base-case estimate of specificity of stool DNA testing was 94\% [16].

\section{Attendance and compliance}

In the light of reality from previous study, as compliance rates and referral rate vary with screening tools, $60 \%$ of compliance rate was assumed for FOBT referring to evidence from several randomised trials [1-4], and $40 \%$ of compliance rate was assumed for sigmoidoscopy and colonoscopy in the light of reality from previous studies $[41,42]$. The compliance with stool DNA testing was assumed to be the same with FOBT. The referral rate to 


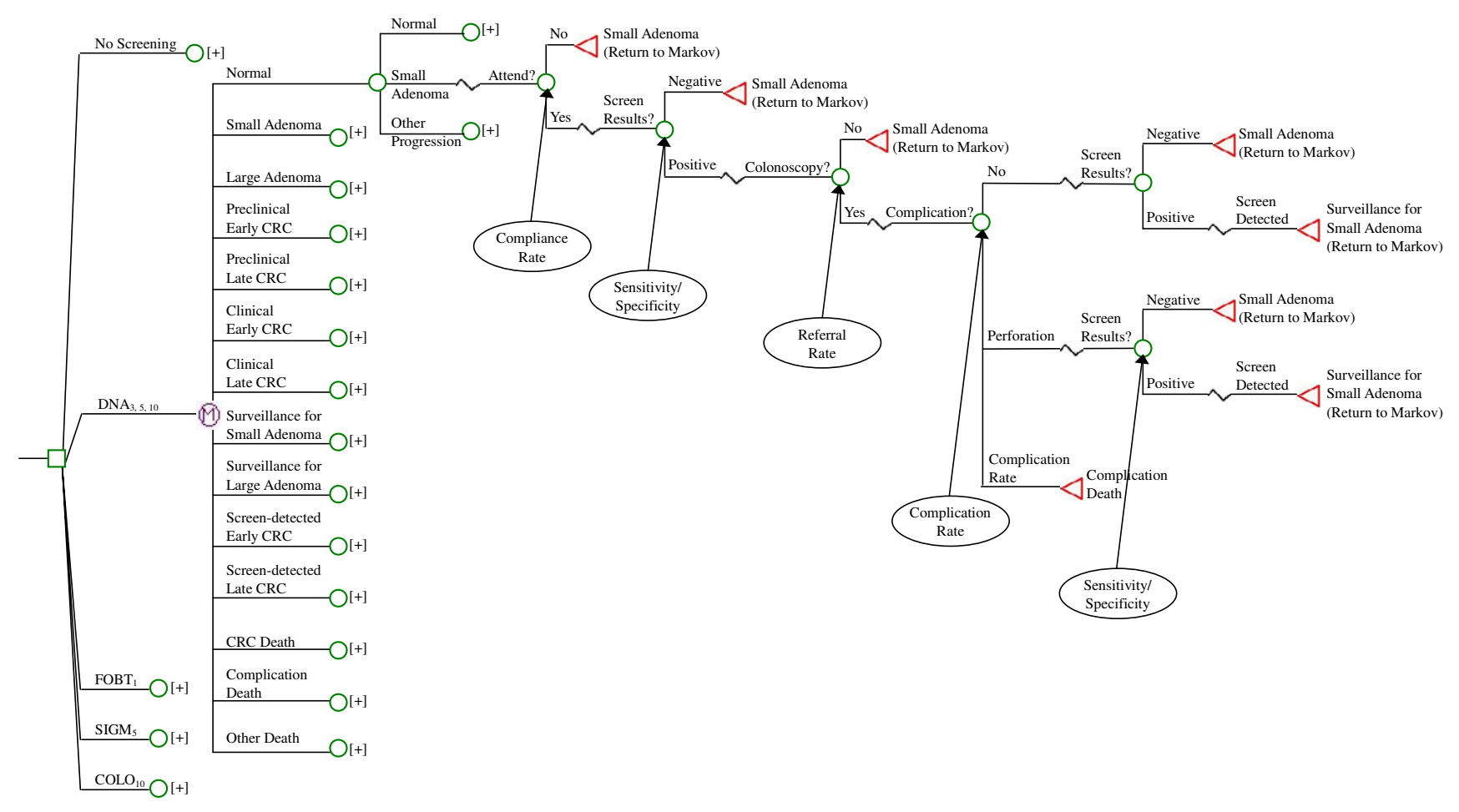

\section{Figure 2}

Structure of decision tree model.** At the beginning of the first Markov cycle, all the probabilities of being in clinical early CRC, clinical late CRC, surveillance for small adenoma, surveillance for large adenoma, screen-detected early CRC, screendetected late CRC, CRC death, complication death, and other death are zero. Ovals are the chance nodes governed by the probability related to compliance rate, sensitivity, specificity, and referral rate.(1): Markov cycle. Abbreviations: CRC, color-

ectal cancer; $\mathrm{DNA}_{3}$, stool DNA testing every 3 years; DNA ${ }_{5}$, stool DNA testing every 5 years; DNA ${ }_{10}$, stool DNA testing every 10 years; $\mathrm{FOBT}_{1}$, fecal occult blood testing every year; SIGM $_{5}$, sigmoidoscopy every 5 years; COLO 10 , colonoscopy every 10 years; Small adenoma, adenoma smaller than I cm in size; large adenoma, adenoma larger than I cm in size; early CRC, Dukes' stage A and B colorectal cancer; late CRC, Dukes' stage C and D colorectal cancer.

diagnostic colonoscopy after positive findings with screening was assumed to be $85 \%$ according to several randomised trials [1-4].

\section{Costs}

Costs are expressed in US dollars ( 1 US dollar $=34$ New Taiwanese dolloar, exchange rate on the basis of the year 2004). As the cost-effectiveness analysis is carried out from the third-party payer perspective only direct costs were calculated in this study, including those relating to the screening itself, treatment and diagnostic tests (adenoma and CRC only), complications from colonoscopy and surveillance (adenoma only). All estimates of cost refer to the price mandated by the Bureau of National Health Insurance in 2004 or expert opinion. Screening costs, except for stool DNA testing, are based on Medicare
Payments by the Bureau of National Health Insurance. The cost of stool DNA testing was estimated by experts after considering the cost of the required laboratory manpower and relevant materials in Taiwan. Treatment and confirmation costs, which relate to polypectomy, biopsy, and pathological examination, were acquired from Medicare Payments by the Bureau of National Health Insurance. The lifetime costs for CRC encompass the initial costs regarding surgery, chemotherapy and radiotherapy, the continuing costs of follow-up after potentially curative therapy, and the eventual cost of terminal care. For the purposes of this costing, expenditure on terminal care is only included for those who (in our models) die from CRC. For early CRC, the initial cost includes only surgery. All future costs and life-years were discounted to the present value at an annual rate of $3 \%$. 


\section{Cost-effectiveness analysis} Incremental cost-effectiveness ratio

The comparisons between the "No Screening" and other screening strategies were first evaluated on the basis of the incremental cost-effectiveness ratio (ICER), which is defined as the difference between the two screening groups in terms of cost divided by the difference between them in terms of effectiveness, i.e. the extra cost required to save additional life-years. The ICERs for stool DNA testing as compared to the other screening strategies were also calculated. A cost of $\$ 13,000$ per life-year saved, which is approximately equivalent to per capita GNP in Taiwan in 2003, was chosen as the ceiling ratio for assessing whether the program is cost-effective.

\section{Sensitivity analysis}

As several parameters are uncertain, including the prevalence of colorectal neoplasm at age 50 years, transition rates, sensitivity and specificity of screening tool, cost of per unit of stool DNA testing, compliance to screening tool, referral rate to diagnostic colonoscopy, and cost of treatment, a series of one-way sensitivity analyses were performed to assess the influence of changing these parameters on the ICER results. The ranges of variables used in sensitivity analysis are shown in Table 1 . Note that improved or worsened sensitivity for small adenoma may lead to changes in sensitivity further down the line, for example, with regard to large adenoma. In this study we assume that any changes in sensitivity to detect small adenoma are paralleled by an equivalent change in sensitivity to detect large adenoma. Similar assumptions were made regarding early and late invasive cancer.

Furthermore, as the previous studies have rather dissimilar estimates for sensitivity and specificity of stool DNA testing, sensitivity analyses were emphasized on the demonstration of the influence of sensitivity and specificity regarding stool DNA testing using the moderate case scenario in which the sensitivities and specificity were obtained from the meta-analysis based on previous studies $[10-13,16]$, and the best case scenario, in which the sensitivities were mainly based on the estimates from Ahlquist study [10] except that the sensitivity of small adenoma was also based on Imperiale study [16]. The sensitivity of stool DNA testing for small adenoma, large adenoma, and colorectal cancer, and the specificity are $8 \%, 18 \%, 85 \%$, and $94 \%$ in the moderate case scenario. The corresponding estimates in the best case scenario are $8 \%, 82 \%, 91 \%$, and $93 \%$, respectively.

As the compliance varies with the screening tool and county, it is important to explore the influence of compliance rate to each screening tool. Therefore, a range of values between $10 \%$ and $100 \%$ were used in the sensitivity analysis to assess the impact of compliance with each screening tool.

\section{Results}

The model predicted that the cumulative incidence of CRC in ages 50 to 75 years, would be 36 per 1,000, which is close to the observed cumulative incidence of CRC in Taiwan (Taiwan Cancer Registry, 37 per 1,000) (Figure 3) [17].

\section{Base-case analysis}

Table 2 shows the simulated number of total cases of CRC, predicted number of CRC deaths, and perforation related deaths, in a cohort of 100,000 persons sub-classified by screening strategy, given $60 \%$ of compliance rate with $\mathrm{FOBT}_{1}, \mathrm{DNA}_{3}, \mathrm{DNA}_{5}$, and $\mathrm{DNA}_{10}, 40 \%$ of compliance rate with $\mathrm{SIGM}_{5}$ and $\mathrm{COLO}_{10}$, and $85 \%$ of referral rate after a positive screening results. $\mathrm{COLO}_{10}$ and $\mathrm{FOBT}_{1}$ have similar effect on CRC mortality with 39\% reduction which is the greatest one among all the screening strategies. $\mathrm{DNA}_{10}$ is the least effective screening strategy. The reductions in incidence with screening, compared to no screening, were very similar. However, stool DNA testing and FOBT reduces CRC incidence by far less than CRC mortality because of its poor sensitivity for adenoma.

The ICERs for other screening strategies, as compared to "No Screening" are also listed in Table 2. In this setting, $\mathrm{COLO}_{10}$ and $\mathrm{FOBT}_{1}$ are both the most cost-effective strategies which are more effective and less costly than No Screening. The incremental costs for $\mathrm{DNA}_{3}, \mathrm{DNA}_{5}$, and $\mathrm{DNA}_{10}$, respectively, were calculated as $\$ 9,794, \$ 9,335$, and $\$ 7,717$ per life-year saved, which is much less costeffective than other screening strategies. Stool DNA testing

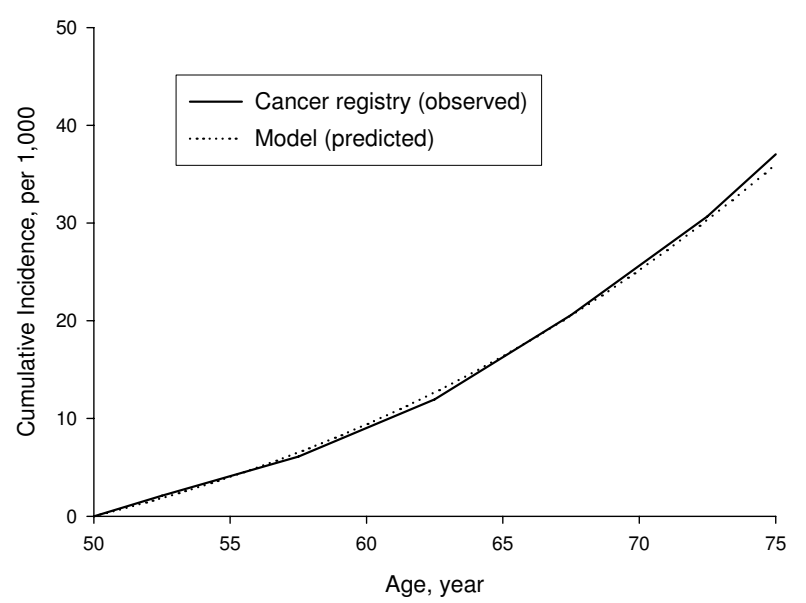

Figure 3

Comparison of observed and predicted cumulative colorectal cancer incidence. 
Table 2: Simulated results for screening strategies to prevent CRC*

\begin{tabular}{|c|c|c|c|c|c|c|c|}
\hline \multirow[t]{2}{*}{ Variable } & \multicolumn{7}{|c|}{ Screening Strategy } \\
\hline & No Screening & $\mathrm{DNA}_{3}$ & $\mathrm{DNA}_{5}$ & $\mathrm{DNA}_{10}$ & FOBT $_{1}$ & $\mathrm{SIGM}_{5}$ & $\mathrm{COLO}_{10}$ \\
\hline Total cases of CRC, $n$ & 2,917 & 2,435 & 2,654 & 2,710 & 2,129 & 2,253 & $\mathrm{I}, 780$ \\
\hline CRC deaths, $n$ & 1,729 & 1,345 & $\mathrm{I}, 467$ & $\mathrm{I}, 574$ & 1,059 & $\mathrm{I}, 328$ & 1,077 \\
\hline Perforation deaths, $n$ & 0 & 3 & 2 & $\mathrm{I}$ & 5 & 3 & 12 \\
\hline Reduction in CRC incidence, \% & 0 & 17 & 9 & 7 & 27 & 23 & 39 \\
\hline Reduction in CRC mortality, \% & 0 & 22 & 15 & 9 & 39 & 23 & 39 \\
\hline Life expectancy, year & 15.7337 & 15.7476 & 15.7434 & 15.7400 & 15.7584 & 15.7477 & 15.7590 \\
\hline Total costs, thousand $\$$ & 22,022 & 35,637 & 31,077 & 26,856 & 19,824 & 24,909 & 21,843 \\
\hline Incremental life-year saved, year & 0 & 1,390 & 970 & 626 & 2,464 & 1,383 & 2,530 \\
\hline Incremental cost, thousand $\$$ & 0 & 13,615 & 9,054 & 4,834 & $-2,198$ & 2,887 & -180 \\
\hline $\begin{array}{l}\text { Incremental cost }(\$) / \text { life-years saved compared with no } \\
\text { screening }\end{array}$ & 0 & 9,794 & 9,335 & 7,717 & Dominant $\ddagger$ & 2,087 & Dominant $\ddagger$ \\
\hline \multicolumn{8}{|l|}{ Incremental cost $(\$) /$ life-years saved: } \\
\hline $\mathrm{DNA}_{3} \mathrm{vs}$. other screening strategies & -- & -- & -- & -- & Dominant $\dagger$ & Dominant $\dagger$ & Dominant $\dagger$ \\
\hline $\mathrm{DNA}_{5}$ vs. other screening strategies & -- & -- & -- & -- & Dominant $†$ & Dominant $†$ & Dominant $\dagger$ \\
\hline$D_{N A}$ vs. other screening strategies & -- & -- & -- & -- & Dominant $\dagger$ & Dominant $\dagger$ & Dominant $\dagger$ \\
\hline
\end{tabular}

Abbreviations: CRC, colorectal cancer; $\mathrm{DNA}_{3}$, stool DNA testing every 3 years; $\mathrm{DNA}_{5}$, stool DNA testing every 5 years; DNA 10 , stool DNA testing every 10 years; $\mathrm{FOBT}_{1}$, fecal occult blood testing every two year; SIGM $_{5}$, sigmoidoscopy every 5 years; COLO 10 , colonoscopy every 10 years.

* Values obtain from a cohort of 100,000 persons 50 years of age who were followed for 25 years.

† The other screening strategy is more effective and less costly than stool DNA testing strategy.

† The screening is more effective and less costly than No Screening.

strategies were out-performed by all the other screening strategies. However, all screening strategies (including stool DNA testing) are cost-effective compared to No Screening.

\section{Sensitivity analysis}

For identifying the influential parameters on ICER for stool DNA testing compared with No Screening, a series of sensitivity analyses were carried out (see Table 3 ). When the cost per stool DNA test is larger than $\$ 57.1$, referral rate with diagnostic colonoscopy is lower than $67 \%$, and prevalence of large adenoma at age 50 years is smaller than $2.42 \%, \mathrm{DNA}_{3}$ was not cost-effective compared to $\$ 13,000$ per life-year saved. Similar ICER estimates were obtained for comparisons between $\mathrm{DNA}_{5}, \mathrm{DNA}_{10}$, and No Screening. Besides, the discount rate also has great influ-

Table 3: One-way sensitivity analysis.

\begin{tabular}{|c|c|c|c|c|c|c|c|c|}
\hline \multirow[t]{3}{*}{ Variables } & \multirow{3}{*}{$\begin{array}{l}\text { Base- Case } \\
\text { Values }\end{array}$} & \multirow{3}{*}{$\begin{array}{c}\text { Sensitivity } \\
\text { Analysis Values }\end{array}$} & \multicolumn{6}{|c|}{ Incremental Cost(\$)/Life-Year Saved } \\
\hline & & & \multicolumn{2}{|c|}{$\mathrm{DNA}_{3}$} & \multicolumn{2}{|c|}{$\mathrm{DNA}_{5}$} & \multicolumn{2}{|c|}{$\mathrm{DNA}_{10}$} \\
\hline & & & Range & Threshold & Range & Threshold & Range & Threshold \\
\hline Base-case & & & 9,794 & & 9,335 & & 7,717 & \\
\hline $\begin{array}{l}\text { Sensitivity of DNA for } \\
\text { small/large adenoma }\end{array}$ & $8 \% / 15 \%$ & $75 \% / 82 \%$ & $11,546-1,742$ & -- & $11,122-1,030$ & -- & $9,369-269$ & -- \\
\hline $\begin{array}{l}\text { Sensitivity of DNA for } \\
\text { preclinical CRC }\end{array}$ & $52 \%$ & $50 \%-100 \%$ & $9,921-7,078$ & -- & $9,454-6,752$ & -- & $7,817-5,528$ & -- \\
\hline Cost per DNA & $\$ 44.1$ & $\$ 22.1-\$ 88.1$ & $4,344-2,0706$ & $\$ 57.1$ & $4,194-19,628$ & $\$ 60.0$ & $3,271-1,6618$ & $\$ 70.3$ \\
\hline Compliance with DNA & $60 \%$ & $10 \%-100 \%$ & $9,070-10,423$ & -- & $9,047-9,582$ & -- & $7,630-7,787$ & -- \\
\hline $\begin{array}{c}\text { Referral rate to } \\
\text { diagnostic colonoscopy }\end{array}$ & $85 \%$ & $10 \%-100 \%$ & $85,266-8,294$ & $67 \%$ & $83,868-7,843$ & $63 \%$ & $73,826-6,396$ & $53 \%$ \\
\hline $\begin{array}{c}\text { Prevalence of large } \\
\text { adenoma }\end{array}$ & $3.82 \%$ & $0.96 \%-7.64 \%$ & $18,969-5,387$ & $2.42 \%$ & $18,184-5,114$ & $2.23 \%$ & $15,657-4,042$ & $1.58 \%$ \\
\hline Discount rate & $3 \%$ & $0 \%-7 \%$ & $6,938-15,674$ & -- & $6,738-14,864$ & -- & $5,107-|3,28|$ & -- \\
\hline
\end{tabular}

$\mathrm{DNA}_{3}$, stool DNA testing every 3 years; $\mathrm{DNA}_{5}$, stool DNA testing every 5 years; DNA 10 , stool DNA testing every 10 years; $\mathrm{FOBT}_{1}$, fecal occult blood testing every two year; SIGM $_{5}$, sigmoidoscopy every 5 years; COLO 10 , colonoscopy every 10 years. 
ence on the ICER of $\mathrm{DNA}_{3}, \mathrm{DNA}_{5}$, and $\mathrm{DNA}_{10}$ compared with No Screening. When the discount rate increases, the ICER of $\mathrm{DNA}_{3}, \mathrm{DNA}_{5}$, and $\mathrm{DNA}_{10}$ increase rapidly.

Since the estimates for sensitivity of stool DNA testing vary from study to study, scenario analyses were conducted to assess the impact of sensitivity of stool DNA testing strategy (see Figure 4). In the moderate case scenario in which the sensitivities and specificity were mainly derived from the meta-analysis based on previous studies $[10-13,16]$, the estimated ICER were similar to the basecase estimates (worst case scenario) which based on Imperiale study [16] (see two bottom curves in Figure 4). The ICER for $\mathrm{DNA}_{3}, \mathrm{DNA}_{5}$, and $\mathrm{DNA}_{10}$ are much less costeffective than other screening strategies but still remained cost-effective compared to No Screening. Assuming the best case scenario in which the sensitivities were mainly based on the estimates from Ahlquist study [10], stool DNA testing strategies became comparable with other screening strategies, and the incremental costs for $\mathrm{DNA}_{3}$, $\mathrm{DNA}_{5}$, and $\mathrm{DNA}_{10}$, respectively, were calculated as $\$ 3,825, \$ 3,036$, and $\$ 2,194$ per life-year saved. $\mathrm{DNA}_{3}$ and

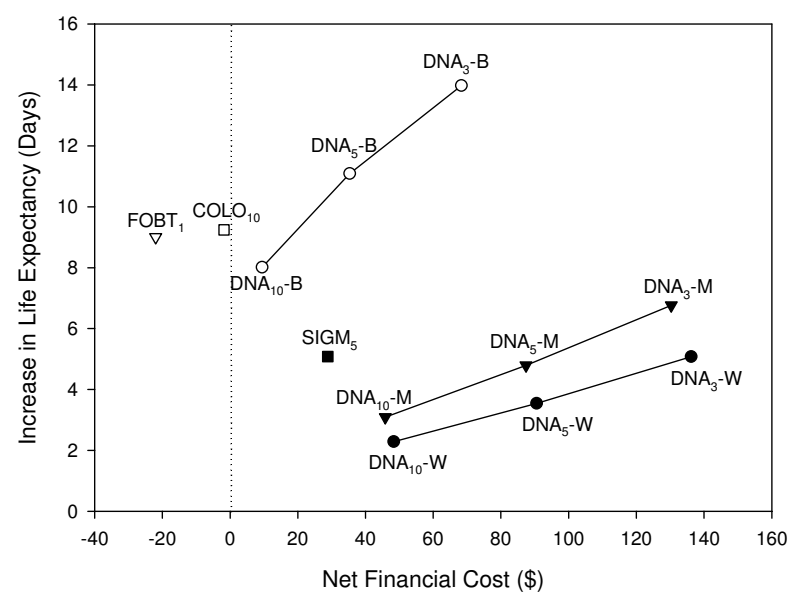

\section{Figure 4}

Cost-effectiveness of CRC screening under different scenarios. Abbreviations: CRC, colorectal cancer; $\mathrm{DNA}_{3}$, DNA $\mathrm{DN}_{5}$, and $D_{N A}$, stool DNA testing every 3,5 , and 10 years, respectively; $-W$, under the worst case scenario (the same with the base-case estimates) in which the sensitivity of stool DNA testing for small adenoma, large adenoma, and colorectal cancer, and the specificity are $8 \%, 15 \%, 52 \%$, and $94 \%$ based on Imperiale et al study [I0]; -M, under the moderate case scenario in which the corresponding estimates are $8 \%$, $18 \%, 85 \%$, and $94 \%$ based on meta-analysis [10-13, 16$] ;-B$, under the best case scenario in which the corresponding estimates are $8 \%, 82 \%, 91 \%$, and $93 \%$ based on Ahlquist et al study [10]; FOBT, fecal occult blood testing every year; $\mathrm{SIGM}_{5}$, sigmoidoscopy every 5 years; $\mathrm{COLO}_{10}$, colonoscopy every 10 years.
DNA $_{5}$ saved more lives than $\mathrm{FOBT}_{1}$ and $\mathrm{COLO}_{10}$, but with high cost

The results of sensitivity analysis regarding compliance rate to each screening tool are illustrated in Figure 5. The effectiveness of $100 \%$ compliance to $\mathrm{FOBT}_{1}$ is approximately equivalent to $\mathrm{COLO}_{10}$ with $60 \%$ compliance rate. SIGM $_{5}$ with $80 \%$ compliance is as effective as FOBT $_{1}$ with $60 \%$ compliance and $\mathrm{COLO}_{10}$ with $40 \%$ compliance but with higher cost. $\mathrm{DNA}_{3}$ with $100 \%$ compliance has approximately equivalent effectiveness compared with FOBT $_{1}$ with $50 \%$ compliance and $\mathrm{COLO}_{10}$ with $30 \%$ compliance but with much higher cost. The corresponding figures were $\mathrm{FOBT}_{1}$ with $30 \%$ compliance and $\mathrm{COLO}_{10}$ with $20 \%$ compliance for $\mathrm{DNA}_{5}$, and were FOBT 1 with $20 \%$ compliance and $\mathrm{COLO}_{10}$ with $15 \%$ compliance for $\mathrm{DNA}_{10}$.

\section{Discussion}

The present study is a formal economic evaluation of $\mathrm{DNA}_{3}, \mathrm{DNA}_{5}$, and $\mathrm{DNA}_{10}$ in relation to several alternatives (No Screening, FOBT 1, SIGM $_{5}$, and COLO $_{10}$ ) using Taiwanese data on colorectal cancer incidence and disease natural history, sub-classified by adenoma size and Dukes' stage in invasive carcinoma. The findings from this study suggest that all of the screening strategies are reasonably cost-effective in relation to No Screening. However, the stool DNA testing strategies were the least cost-effective. $\mathrm{COLO}_{10}$ and $\mathrm{FOBT}_{1}$ are the most cost-effective strategy. Nevertheless, the feasibility of opting for

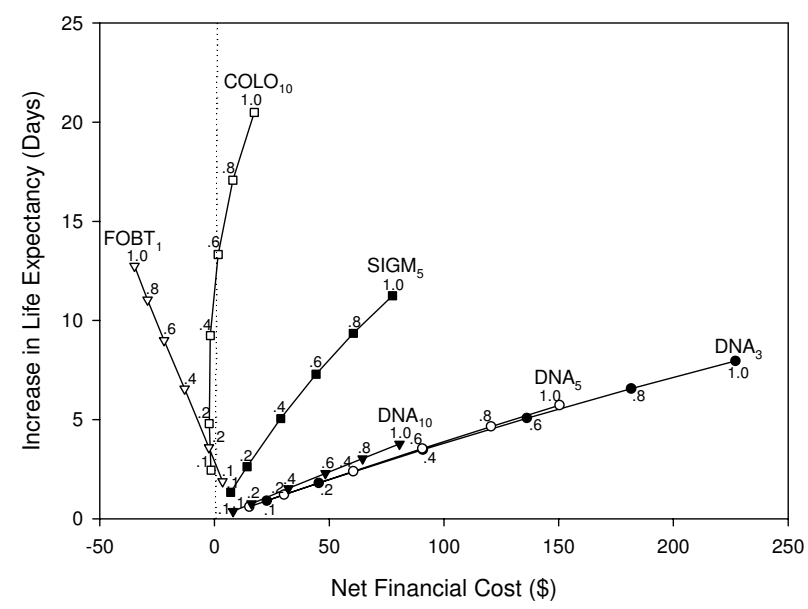

Figure 5

Sensitivity analysis regarding compliance to screening tool (0.I, 0.2, 0.4, 0.6, 0.8, and I.0). Abbreviations: $\mathrm{DNA}_{3}$, stool

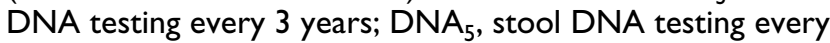
5 years; $\mathrm{DNA}_{10}$, stool DNA testing every 10 years; $\mathrm{FOBT}_{1}$, fecal occult blood testing every year; SIGM $_{5}$, sigmoidoscopy every 5 years; COLO 10 , colonoscopy every 10 years. 
colonoscopy as screening tool for average-risk groups may be questionable due to the shortage of medical endoscopic manpower and the risk of perforation associated with colonoscopy. Stool DNA testing would be preferable to the other screening strategies if the sensitivity for both adenoma and CRC were high enough, as seen in the best case scenario of sensitivity analysis from the Ahlquist study [10], and if the cost of the test could be lowered through economies of scale like the example of hepatitis $B$ vaccination the price of which has dramatically fallen due to the advent of universal program in 1990s [43]. However, the interpretation of the finding in the best case scenario should be taken with great caution because subjects enrolled in Ahlquist study [10] was based on clinical series patients rather than asymptomatic subjects from average-risk population [16].

It should be noted that our focus on this study was to assess whether stool DNA testing was cost-effective provided stool DNA testing can be used as another alternative choice for population-based screening. The incremental cost-effectiveness analysis by pairwise comparison across different screening tools (i.e. colonoscopy vs. stool DNA testing) was therefore not attempted.

Although stool DNA testing has been proposed in recent years its application to mass screening for colorectal cancer has not been evaluated. The major deterrent has been doubt over the performance of test. Previous studies show a wide range of sensitivities for stool DNA testing, ranging from $15 \%$ to $82 \%$ for large adenoma and from $50 \%$ to $100 \%$ for invasive CRC $[10-13,16]$. This variation may often be attributed to differences in the way asymptomatic subjects or symptomatic cases were selected, although this was not the case in the Imperiale et al study [16]. The largest study to focus on asymptomatic subjects (the major target of mass screening) showed $8 \%$ sensitivity for small adenoma, $15 \%$ for large adenoma and 52\% for invasive CRC [16]. False negative cases, as a result of low sensitivity, may lower its effectiveness as a tool for screening asymptomatic subjects in the general population. However, to integrate state-of-world information obtained form previous studies, we used the meta-analysis to obtain the estimate by taking all previous studies into account as the moderate case scenario. However, the estimate of sensitivity of adenoma has been largely affected by the Imperial study [16] because it is the largest study up to date on screening for colorectal cancer with stool DNA testing. The estimate based on meta-analysis for the sensitivity of cancer has been estimated as $85 \%$ by weighting the inverse variance of each study.

It could be argued that stool DNA testing screening is to be more expensive than other screening tools. This may be true at the inception of screening strategy but with wide- spread use, we might reasonably expect savings due to economies of scale. Genetic epidemiology is still in its infancy but the development of genetic chip technology and DNA testing advances may soon facilitate the development of simple commercial stool DNA testing kits, which would be considerably cheaper.

Very few studies have addressed the economic aspects of adopting stool DNA testing as screening tool for use in the general population. Only Song et al [44] and Leshno et al [45] have performed a study on cost-effectiveness, comparing fecal DNA testing with conventional CRC screening. The parameters in the former study are based on Western countries with a high prevalence of CRC, and the parameters in the latter study are based on Israel which also has a high incidence rate of CRC [46]. To the best of our knowledge, no similar studies on stool DNA testing have been conducted in countries with low or intermediate incidence of CRC. Furthermore, the base-case estimates of sensitivity and specificity for stool DNA testing may vary across studies. The sensitivity and the specificity used in Leshno study are 70\%, 82\%, 91\%, and 90\% for small adenoma, large adenoma, preclinical CRC, and specificity, respectively, which were similar to our best case scenario, and only annual stool DNA testing has been considered [45]. The corresponding estimates in Song study are $40 \%, 40 \%, 65 \%$, and 95\%, respectively [44]. Compared with the two previous studies [44,45], the base-case estimates in our study are the most conservative ones which only base on the population-based study [16]. However, despite the diversified parameter regarding sensitivity and specificity, our findings that stool DNA testing is cost-effective compared to No Screening but inferior to conventional screening methods such as FOBT and colonoscopy are consistent with Song et al's and Leshno et al's findings $[44,45]$.

The reported ICERs in this study are much lower than that reported in other cost-effectiveness analysis [44,47,48]. This discrepancy can be explained by the low cost of screening tool, and other relevant cost for CRC treatment and diagnosis used in this study which represents the reality in Taiwan. When we used the cost based on the Western country as our base-case parameters [44], given perfect compliance and perfect referral rate as assumed in the previous studies, the ICERs are comparable with the previous studies $[44,47,48]$. The ICER for $\mathrm{FOBT}_{1}, \mathrm{SIGM}_{5}$, and $\mathrm{COLO}_{10}$ compared with No Screening are estimated as $\$ 2,376, \$ 20,206$ and $\$ 13,831$ per life-year saved, respectively. However, all the stool DNA testing strategies are not cost-effective and the ICERs inflate to approximately $\$ 115,000$ per life-year saved for $\mathrm{DNA}_{10}$ compared with No Screening. 
The compliance may have large influence on the cost and the effectiveness of a screening program. Nevertheless, the compliance may vary widely by different screening tool and population [49], therefore, the decision should be made by the preference of each population. Figure 5 has shown the influence of different compliance level of each screening tool on the cost-effectiveness which allows the assessment for various compliance rates to each screening tool. For example, for a population with the compliance of $40 \%$ with FOBT 1 and of $20 \%$ with SIGM $_{5}$ and COLO $_{10}$ FOBT $_{1}$ would save more lives and less costly than all the other screening strategies. However, for a population with the compliance of $50 \%$ with $\mathrm{FOBT}_{1}$ and of $40 \%$ with $\mathrm{SIGM}_{5}$ and $\mathrm{COLO}_{10}, \mathrm{COLO}_{10}$ would have more life-year gained than $\mathrm{FOBT}_{1}$ but with higher cost.

As far as the validity of our simulation model is concerned, our results obviously depend on the parameters chosen for the natural history part of the model. Three findings lead us to believe that our simulated model is adequate. Firstly, the predicted cumulative incidence of CRC in our study, 34 per 1,000, is close to the observed one, 37 per 1,000 [17]. Secondly, our sensitivity analyses demonstrates that changes to the upper and lower bounds of our estimates do not lead to substantial changes in our results. Thirdly, to check whether our simulated results on the effectiveness of FOBT test are consistent with those reported in several randomized trials [1-4], we applied $60 \%(56.5 \%$ 67\%) compliance rate of FOBT and 85\% referral rate to diagnostic colonoscopy and identical transition parameters based on base-case parameters, and shortened follow-up year to 10 years as seen in randomized trial, the predicted mortality reduction for annual FOBT screening and biennial FOBT screening is $20 \%$ and $13 \%$, respectively, the latter of which is close to the findings from several randomised trials with two-yearly interscreening interval, indicating $16 \%, 21 \%$, and $15 \%$ mortality reduction conducted in Burgundy (France) [4], Funen (Denmark) [3], and Nottingham (UK) [2], respectively. For the incidence, the incidence ratio was estimated as 0.80 (annual FOBT) after follow-up for 18 years, which was close to the estimate reported in randomized trial [1].

Since this study was conducted from a third-party payer perspective, we therefore adopted the price mandated by the Bureau of National Health Insurance $(95 \%$ population covered) as the cost and only direct costs were included. However, indirect costs such as production loss due to attending to screening or due to disease should be considered from the societal viewpoint. This could be the subject of future studies.

Our study has, however, one limitation as our proposed model assumes an adenoma to carcinoma sequence, which accounts for the majority of CRCs. Non-polypoid cases are not taken into account. However, as only a fraction of CRCs are non-polypoid and the cost-effectiveness analysis addresses the relative comparisons across screening strategies, the incorporation of the occurrence of nonpolypoid tissue is unlikely to substantially affect the results.

\section{Conclusion}

In conclusion, an economic evaluation of CRC screening with stool DNA testing was performed in a country with an intermediate incidence of CRC. Our results suggest that stool DNA testing is less cost-effective than other currently recommended strategies for population-based averagerisk subjects.

\section{Competing interests}

The author(s) declare that they have no competing interests.

\section{Authors' contributions}

GHMW is responsible for the study design, statistical modeling, data interpretation and drafting of the article. YMW is responsible for collection and assembly of data. AMFY is responsible for statistical expertise. JMW and HCL both make great contribution to critical revision of the article for important intellectual content. JW assisted in interpreting the data and revising the article. THHC makes great contribution to conception and design, critical revision of the article for important intellectual content, statistical expertise, interpreting results, and revising manuscript.

\section{Acknowledgements}

The author(s) thank Dr. Chao-Sheng Liao, Shin Kong Wu Ho-Su Memorial Hospital, Taipei, for acquisition of data on cost. This study has not been supported by any research fund.

\section{References}

I. Mandel JS, Bond JH, Church TR, Snover DC, Bradley GM, Schuman LM, Ederer F: Reducing mortality from colorectal cancer by screening for fecal occult blood. $N$ Engl J Med 1993, 328: $1365-137 \mid$.

2. Hardcastle JD, Chamberlain JO, Robinson MH, Moss SM, Amar SS, Balfour TW, James PD, Mangham CM: Randomised controlled trial of faecal-occult-blood screening for colorectal cancer. Lancet 1996, 348: 1472-1477.

3. Kronborg O, Fenger C, Olsen J, Jorgensen OD, Sondergaard O: Randomised study of screening for colorectal cancer with faecaloccult-blood test. Lancet 1996, 348:|467-71.

4. Faivre J, Dancourt V, Lejeune C, Tazi MA, Lamour J, Gerard D, Dassonville $\mathrm{F}$, Bonithon-Kopp C: Reduction in colorectal cancer mortality by fecal occult blood screening in a French controlled study. Gastroenterology 2004, I 26:1674-80.

5. Rudy DR, Zdon MJ: Update on colorectal cancer. Am Fam Physician 2000, 61:1759-1770.

6. Selby JV, Friedman GD, Quesenberry CPJ, Weiss NS: A case-control study of screening sigmoidoscopy and mortality from colorectal cancer. N Engl J Med 1992, 326:653-657.

7. Müller $A D$, Sonnenberg $A$ : Protection by endoscopy against death from colorectal cancer. A case-control study among veterans. Arch Intern Med 1995, I 55:1741-1748.

8. Winawer S, Fletcher R, Rex D, Bond J, Burt R, Ferrucci J, Ganiats T, Levin T, Woolf S, Johnson D, Kirk L, Litin S, Simmang C, Gastrointes- 
tinal Consortium Panel: Colorectal cancer screening and surveillance: clinical guidelines and rationale - Update based on new evidence. Gastroenterology 2003, I 24:544-560.

9. American Cancer Society: American Cancer Society guidelines on screening and surveillance for the early detection of adenomatous polyps and colorectal cancer - update 200 I. CA: A Cancer I for Clinicians 200 I, 5 I:44-54.

10. Ahlquist DA, Skoletsky JE, Boynton KA, Harrington JJ, Mahoney DW, Pierceall WE, Thibodeau SN, Shuber AP: Colorectal cancer screening by detection of altered human DNA in stool: feasibility of a multitarget assay panel. Gastroenterology 2000 I | 9: I219-1227.

II. Tagore KS, Lawson MJ, Yucaitis JA, Gage R, Orr T, Shuber AP, Ross ME: Sensitivity and specificity of a stool DNA multitarget assay panel for the detection of advanced colorectal neoplasia. Clin Colorectal Cancer 2003, 3:47-53.

12. Loktionov A, O'Neill IK, Silvester KR, Cummings JH, Middleton SJ, Miller R: Quantitation of DNA from exfoliated colonocytes isolated from human stool surface as a novel noninvasive screening test for colorectal cancer. Clin Cancer Res 1998, 4:337-342.

13. Koshiji M, Yonekura Y, Saito T, Yoshioka K: Microsatellite analysis of fecal DNA for colorectal cancer detection. J Surg Oncol 2002, 80:34-40.

14. Dong SM, Traverso G, Johnson C, Geng L, Favis R, Boynton K, Hibi K, Goodman SN, D'Allessio M, Paty P, Hamilton SR, Sidransky D, Barany F, Levin B, Shuber A, Kinzler KW, Vogelstein B, Jen J: Detecting colorectal cancer in stool with the use of multiple genetic targets. I Natl Cancer Inst 200 I, 93:858-865.

15. Traverso G, Shuber A, Levin B, Johnson C, Olsson L, Schoetz DJ Jr, Hamilton SR, Boynton K, Kinzler KW, Vogelstein B: Detection of APC mutations in fecal DNA from patients with colorectal tumors. N Engl J Med 2002, 346:3 I I-320.

16. Imperiale TF, Ransohoff DF, Itzkowitz SH, Turnbull BA, Ross ME: Fecal DNA versus fecal occult blood for colorectal-cancer screening in an average-risk population. N Engl J Med 2004 , 35 I:2704-27|4

17. Cancer registry annual report Republic of China. Taipei: Department of Health, Republic of China; 2003.

18. Cox DR, Miller HD: The theory of stochastic processes. Methuen and Co Ltd; 1965

19. Duffy SW, Tabar L, Day NE: Estimation of mean sojourn time in breast cancer screening using a Markov chain model of both entry and exit from the preclinical detectable phase. Stat Med 1995, | 4: I53|-I543.

20. Chen THH, Kuo HS, Yen MF, Lai MS, Tabar L, Duffy SW: Estimation of sojourn time in chronic disease screening without data on interval cases. Biometrics 2000, 56:167-172.

21. Stryker SJ, Wolff BG, Culp CE, Libbe SD, Ilstrup DM, MacCarty RL: Natural history of untreated colonic polyps. Gastroenterology 1987, 93:1009-13.

22. Chen TH, Yen MF, Lai MS, Koong SL, Wang CY, Wong JM, Prevost TC, Duffy SW: Evaluation of a selective screening for colorectal carcinoma: the Taiwan Multicenter Cancer Screening (TAMCAS) project. Cancer 1999, 86: I I I6-II 28.

23. O'Connell JB, Maggard MA, Ko CY: Colon cancer survival rates with the new American Joint Committee on Cancer six edi tion staging. J Nalt Cancer Inst 2004, 96: |420-5.

24. 2002 Health and Vital Statistics. Taipei: Department of Health, Republic of China; 2003

25. Winawer SJ, Fletcher RH, Miller L, Godlee F, Stolar MH, Mulrow CD, Woolf SH, Glick SN, Ganiats TG, Bond JH, Rosen L, Zapka JG, Olsen SJ, Giardiello FM, Sisk JE, Van Antwerp R, Brown-Davis C, Marciniak DA, Mayer RJ: Colorectal cancer screening: clinical guidelines and rationale. Gastroenterology 1997, I I 2:594-642.

26. Ahlquist DA, Wieand HS, Moertel CG, McGill DB, Loprinzi CL, O'Connell MJ, Mailliard JA, Gerstner JB, Pandya K, Ellefson RD: Accuracy of fecal occult blood screening for colorectal neoplasia. JAMA 1993, 269:1262-1267.

27. Ahlquist DA: Fecal occult blood testing for colorectal cancer: can we afford to do this? Gastroenterol Clin North Am 1997, 26:4l-55.

28. Launoy G, Smith TS, Duffy SW, Bouvier V: Colorectal cancer mass-screening: estimation of faecal occult blood test sensitivity, taking into account cancer mean sojourn time. Int Cancer 1997, 73:220-4.
29. Gyrd-Hansen D, Sogaard J, Kronborg L: Analysis of screening data: colorectal cancer. Int J Epidemiol I997, 26(6): I I 72-8I

30. Moss SM, Hardcastle JD, Coleman DA, Robinson MHE, Rodrigues VC: Interval cancers in a randomized controlled trail of screening for colorectal cancer using a faecal occult blood test. Int J Epidemiol 1999, 28:386-90.

3I. Jouve JL, Remontet L, Dancourt V, Lejeune C, Benhamiche AM, Faivre J, Esteve J: Estimation of screening test (Hemoccult) sensitivity in colorectal cancer mass screening. Brit J Cancer 200I, 84(I I): |477-8|

32. Foutch PG, Mai H, Pardy K, DiSavio JA, Manne RK, Kerr D: Flexible sigmoidoscopy may be ineffective for secondary prevention of colorectal cancer in asymptomatic, average-risk men. Dig Dis Sci 1991, 86:946-95I.

33. Rex DK, Cutler CS, Lemmel GT, Rahmani EY, Clark DW, Helper DJ, Lehman GA, Mark DG: Colonoscopic miss rates of adenomas determined by back-to back colonoscopies. Gastroenterology 1997, I | 2:24-28.

34. Hixson LJ, Fennerty MB, Sampliner RE, Garewal HS: Prospective blinded trial of the colonoscopic miss-rate of large colorectal polyps. Gastrointest Endosc 1991, 37:125-127.

35. Rex DK: Colonoscopy: a review of its yield for cancers and adenomas by indication. Am / Gastroenterol 1995, 90:353-365.

36. Castiglione G, Ciatto S, Mazzotta A, Grazzini G: Sensitivity of screening sigmoidoscopy for proximal colorectal tumors. Lancet 1995, 345(895 I):726-7.

37. Zarchy TM, Erchoff D: Do characteristics of adenomas on flexible sigmoidoscopy predict advanced lesions on baseline colonoscopy? Gastroenterology 1994, I 06(6): I50|-4.

38. Achkar E, Carey W: Small polyps found during fiberoptic sigmoidoscopy in asymptomatic patients. Ann Intern Med 1988 I 09:880-883.

39. Pignone M, Saha S, Hoerger T, Mandelblatt J: Cost-effectiveness analyses of colorectal cancer screening: a systematic review for the U.S. Preventive Services Task Force. Ann Intern Med 2002, I37:96-104.

40. Kirschner CG, Davis SJ, Duffy C, Evans D, Hayden D, Jackson JA Jacobs SJ, Jacobson CA, Kopacz J, Kotowicz GM, O'Heron MR, O'Hara KE, Reyes D: Current Procedural Terminology: CPT. Chicago: American Medical Assoc; 1999.

4I. Blom J, Liden A, Jeppsson B, Holmberg L, Pahlman L: Compliance and findings in a Swedish population screened for colorectal cancer with sigmoidoscopy. EJSO 2002, 28:827-3I.

42. Pariente A, Milan C, Jafon J, Faivre : Colonoscopic screening in first-degree relatives of patients with 'sporadic' colorectal cancer: a case-control study. Gastroenterology 1998, I I 5:7-I2.

43. World Health Organization: Immunization, vaccines and biologicals. The history of vaccination. [http://www.who.int/vaccinesdiseases/history/history.shtml]. Accessed March I, 2006.

44. Song K, Fendrick AM, Ladabaum U: Fecal DNA testing compared with conventional colorectal cancer screening methods: a decision analysis. Gastroenterology 2004, I 26: I270-I 279.

45. Leshono M, Halpern Z, Arber N: Cost-effectiveness of colorectal cancer screening in the average risk population. Health Care Manag Scien 2003, 6:165-74.

46. Parkin DM, Bray F, Ferlay J, Pisani P: Global cancer statistics, 2002. CA Cancer J Clin 2005, 55:74-I08.

47. Sonnenberg A, Delco F, Inadomi JM: Cost-effectiveness of colonoscopy in screening for colorectal cancer. Ann Intern Med 2003, I 33:573-584

48. Vijan S, Hwang EW, Hofer TP, Hayward RA: Which colon cancer screening test? A comparison of costs, effectiveness, and compliance. Am J Med 200 I, I I I:593-60 I.

49. Vernon SW: Participation in colorectal cancer screening: a review. J Natl Cancer Inst 1997, 89:|406-22.

\section{Pre-publication history}

The pre-publication history for this paper can be accessed here:

http://www.biomedcentral.com/1471-2407/6/136/pre pub 